\title{
The Role of Esterification on Detection of Protonated and Deprotonated Peptide Ions in Matrix Assisted Laser Desorption/Ionization (MALDI) Mass Spectrometry (MS)
}

\author{
Paolo Lecchi and Matthew Olson \\ Department of Pharmacology and Physiology, George Washington University School of Medicine and Health \\ Sciences, Washington, District of Columbia, USA
}

\author{
Francesco L. Brancia \\ Shimadzu Research Laboratory, Manchester, United Kingdom
}

Esterification was used to investigate how introduction of aliphatic chains within the peptide structure affects the MALDI response of ions analyzed in both polarity regimes. In binary mixtures containing equimolar amounts of a peptide with its correspondent alkyl ester, derivatization of the carboxylic groups has the tendency to increase MALDI detection of the modified protonated peptide ions. This positive effect on ion yield is more pronounced when longer alcohols are employed. In negative mode, the situation is antithetic and esterification produces a deleterious effect on the ion yield of the corresponding deprotonated species. From the data reported here we postulate that modifications of the acidic character of peptides prevent formation of anionic species under MALDI analysis. Furthermore, suppression of the formation pathway for anions alters the overall number of molecules which can undergo protonation. This results in an increased ion yield for the protonated esters. (J Am Soc Mass Spectrom 2005, 16, 1269-1274) (C) 2005 American Society for Mass Spectrometry

$\mathrm{T}$ he use of matrix assisted laser/desorption ionization (MALDI) mass spectrometry (MS) is now routine in the structural determination of biological molecules [1, 2]. Despite its utility, the underlying mechanism of the MALDI process remains poorly understood, and no unified model on MALDI ion formation has been accepted widely [3-5]. During ultraviolet excitation, several reactions are known to occur: formation of radical cations via electron-transfer, generation of singly charged ions via protonation, and production of cationized molecules in the form of metal ion adducts $[6,7]$.

Analysis of peptide mixtures remains the major application of MALDI. It has been demonstrated that the type of amino acid incorporated in the peptide backbone influences the abundance of its corresponding ions [8]. In particular, MALDI spectra of peptides derived from trypsin-mediated digestion of proteins showed that the proton affinity of C-terminus amino acids governs their MALDI response, and lysine containing peptides generated by tryptic digestion of pro-

Published online June 22, 2005

Address reprint requests to Dr. F. Brancia, Shimadzu Research Laboratory, Wharfside, Trafford Wharf Road, Manchester M17 1GP, UK. E-mail: Francesco.Brancia@srlab.co.uk teins produce ions detected in lesser abundance than those incorporating arginine [9]. To improve sensitivity, conversion of the $\varepsilon$-amino group on lysine to a guanidino moiety led to an improvement of the ionization efficiency of the derivatized macromolecules [10]. Increase in detection resulting from chemical modification was also exploited in the analysis of sugars [11] and oligonucleotides [12]. Additionally, several exogenous factors, not linked to the peptide chemical nature, play a crucial role in affecting the final appearance of a MALDI spectrum. Matrix solution composition and $\mathrm{pH}$, type of sample preparation, and rate of matrix crystallization can favor or attenuate the MALDI ion yield of peptides present in complex mixtures [13]. Morphological studies of peptide solutions prepared with different matrices and protocols suggested that variations in sensitivity during MALDI analysis are attributable to the hydrophobicity of the peptides [14]. Previously, peptide hydrophobicity was indicated as a plausible cause of the poor ion yield displayed by hydrophilic peptides desorbed in plasma desorption mass spectrometry (PDMS) [15] and fast atomic bombardment (FAB) [16]. Using FAB, Falick and Maltby showed that esterification of hydrophilic peptides was beneficial to detection of the resulting alkyl and benzyl esters [17]. In this paper, we apply a rigorous approach to MALDI to 
evaluate whether the esterification of peptide mixtures is critical in enhancing ion yield.

\section{Experimental}

\section{Materials}

All the chemicals and standard peptides were purchased from Sigma (St. Louis, MO) and used without additional purifications. Additional peptides were obtained by reduction, alkylation, and overnight tryptic digestion of standard proteins (e.g., chicken lysozyme, horse apomyoglobin, and bovine serum albumin) followed by HPLC separation of the proteolytic fragments

\section{Mass Spectrometry}

All MALDI-TOF mass spectra were acquired on an AXIMA CFR instrument (Kratos Analytical, Shimadzu Biotech, Manchester, UK) equipped with a drift tube of $1.2 \mathrm{~m}$. Matrix-assisted laser desorption ionization of peptides was produced by pulses of a nitrogen laser $(\lambda$ $=337 \mathrm{~nm}$, 3ns pulse width) with a maximum pulse rate of $10 \mathrm{~Hz}$. During acquisition the sample target was monitored by a monochrome video-image system $(25 \times$ magnification). The pressure in the ion source was typically held at $1 \times 10^{-6}$ mbar. Spectra were collected in linear mode with 100 ns extraction delay. The accelerating voltage was set to $\pm 20 \mathrm{kV}$ depending on polarity used. Spectra were the sum of 100 profiles automatically acquired rastering the sample spot. Each profile was the result of two consecutive single laser pulses. Acquisition and data processing were controlled by Launchpad software version 2.3 (Kratos Analytical). The TOF was externally calibrated using a mixture of peptides obtained by tryptic digestion of horse apomyoglobin.

\section{Esterification}

Esterification of peptides containing 1 carboxylic moiety was accomplished by dissolving 200 pmol of the peptide in $200 \mu \mathrm{L}$ of a high purity (>99\%) anhydrous alcohol containing $200 \mathrm{mM}$ acetyl chloride. If the peptide contained more than 1 carboxylic group, the same amount was dissolved in $200 \mu \mathrm{L}$ of alcohol containing 1 $\mathrm{M}$ acetyl chloride. All reactions proceeded overnight at room temperature on an orbital mixer set at $50 \mathrm{rpm}$. At completion, the reactions were not quenched with water so as to avoid an equilibrium shift away from the ester during evaporative centrifugation. The alcohol was removed by speed-vac (Savant, Holbrook, NY), and the peptides were reconstituted to $5 \mu \mathrm{M}$ in $0.1 \%$ (vol/vol) trifluoroacetic acid (TFA). $\alpha$-Cyano-4hydroxycinnamic acid (CHCA), 2,5-dihydroxy benzoic acid (DHB), 6 aza-2-thiothymine (ATT), sinapinic acid (SA) were used as matrices: they were prepared as 5 $\mathrm{mg} / \mathrm{ml}$ solutions in $0.1 \% \mathrm{TFA}$ in $50 \%$ (vol/vol) acetonitrile. A portion $(2 \mu \mathrm{L})$ of each sample was mixed with
$2 \mu \mathrm{L}$ of the matrix solution, and an aliquot of $0.5 \mu \mathrm{L}$ was spotted onto a welled stainless steel target and dried at atmospheric pressure.

\section{Results and Discussions}

\section{Influence of Alcohol}

As shown previously in FAB, the ion yield of hydrophilic peptides can be enhanced by esterification [17]. Using a similar procedure, our first goal was to determine whether conversion of the carboxylic groups to the corresponding esters is beneficial to detection of the modified counterparts. To increase hydrophobicity, several standard peptides were derivatized with aliphatic n-alcohols varying in length (i.e., from methanol to 1-hexanol). Because of their tendency to yield incomplete derivatization products and the objective difficulty of evaporating long-chain alcohols, esterification with alcohols containing more than 6 carbons was not attempted extensively. Figure 1 shows the MALDI spectra acquired in linear mode of equimolar mixtures containing angiotensin II (DRVYIHPF) and its alkyl ester analogs. Separate mass spectrometric analyses of the esterified peptides indicate that each reaction goes to completion for all the carboxylate moieties and that no traces of the underivatized peptides are present in the spectrum. Conversely, no formation of ester is detected when the reaction is carried on without acetyl chloride. As shown in Figure 1, even in the presence of two carboxylic groups, the reaction goes to completion with a limited presence of the monoester when shortchain alcohols are utilized (see Figure $1 b$ and c). Consistently, in all the binary mixtures analyzed (i.e., containing equimolar amounts of the peptide and its peptide ester), the peptide ester ions are detected in higher abundance than their underivatized counterparts. Moreover, this difference in ion yield seems to be more pronounced when longer aliphatic chains are introduced in the same peptide. The ester generated by esterification with 1-hexanol produces the highest enhancement in ion signal, reaching up to a tenfold improvement for the hexyl ester. The analyses of samples containing equimolar amounts of the same peptide derivatized with alcohols of different lengths further reveal the correlation between the increase of ion yield and the length of the alkyl chain of the alcohol utilized for the esterification. This trend is well evidenced in Figure 2, which shows the MALDI spectrum of a mixture containing an equimolar amount of different bradykinin esters (from methyl to hexyl). Results of similar analyses conducted with peptides of different composition reveal a consistent correlation between MALDI response and chain length of the alcohol used: the greater peptide hydrophobicity, the higher the observed ion yield. Since the proton affinities of the basic amino acids (i.e., arginine, lysine, histidine) on which protonation occurs are not chemically altered, the comparison of the ion abundances allows to 


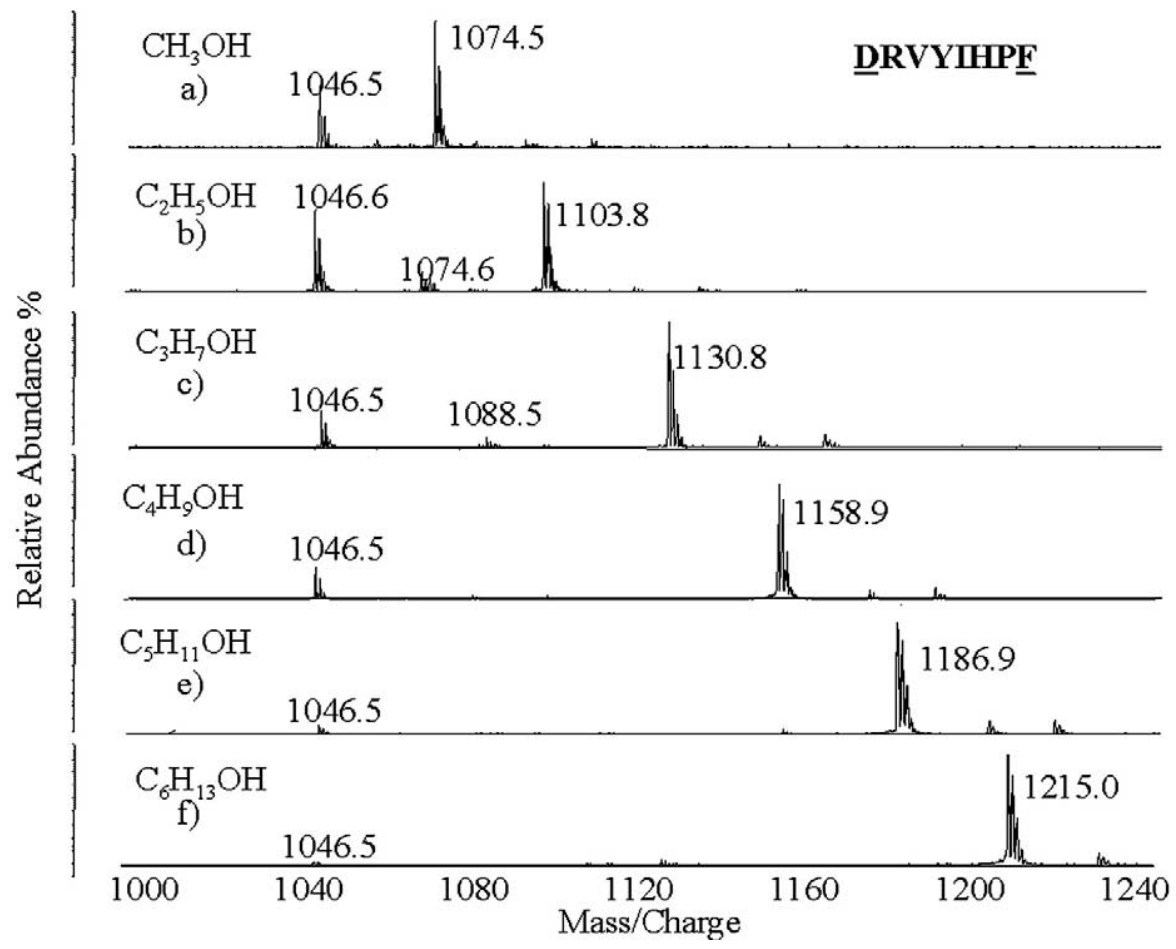

Figure 1. Linear MALDI TOF spectra of binary mixtures (1-1) obtained mixing angiotensin II (DRVYIHPF) $\left([\mathrm{M}+\mathrm{H}]^{+}\right.$at $m / z$ 1046.5) with the corresponding esters. Esterification was performed with methanol (a), ethanol (b), 1-propanol (c), 1-butanol (d), 1-pentanol (e), and 1-hexanol (f), respectively.

isolate the contribution of esterification on ion yield. In our approach, with respect to works published previously [14, 18, 19], all experiments performed indicate that if variations in MALDI response are

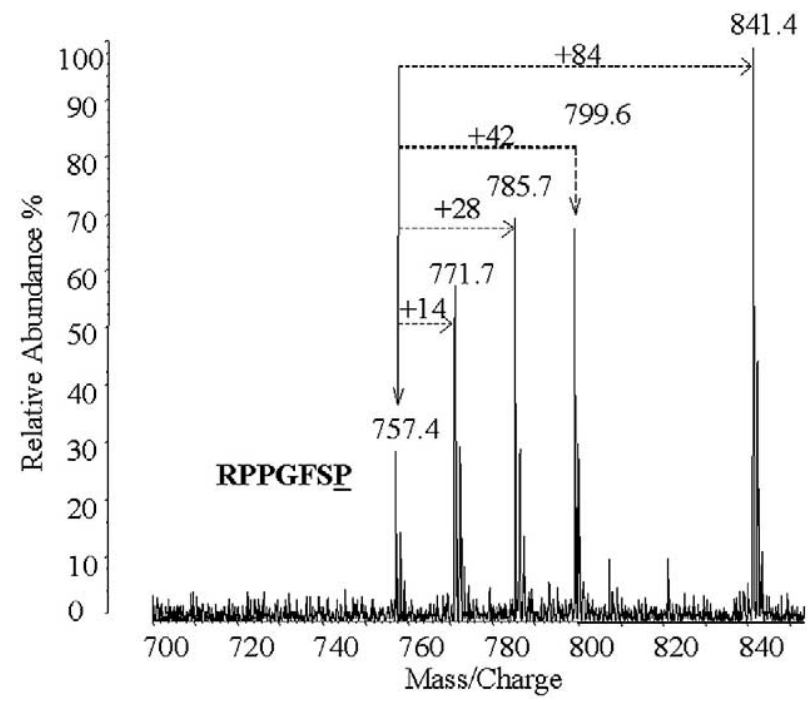

Figure 2. Linear MALDI TOF analysis of an equimolar mixture of bradykinin (RPPGFSP) and its corresponding esters. The presence of the $-\mathrm{COOH}$ residue at $\mathrm{C}$-terminus leads to the formation of esters with the following shifts in $\mathrm{MW}$ methanol $\mathrm{D}_{\mathrm{C} 1}(+14)$, ethanol $\mathrm{D}_{\mathrm{C} 2}(+28)$, 1-propanol $\mathrm{D}_{\mathrm{C} 3}(+42)$, and 1-hexanol $\mathrm{D}_{\mathrm{C} 6}(+84)$ respectively. The underlined amino acids indicate the residues containing carboxylic groups. observed among esters deriving from the same peptide, these discrepancies are attributable to variations in chain length rather than to different proton affinities.

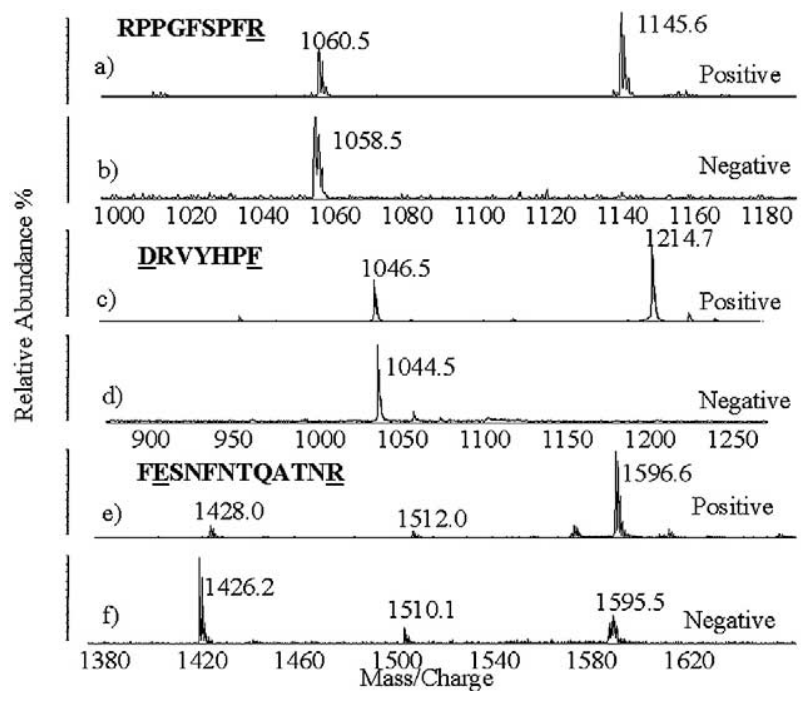

Figure 3. MALDI TOF spectra of binary equimolar mixtures containing a peptide and its hexyl ester acquired in positive (top) and negative mode (bottom). Examples reported for peptide/ peptide esters of (a) (b), bradykinin (RPPGFSPFR), (c) (d), angiotensin II (DRVYIHPF), and (e) (f), lysozyme fragment 34-45 (FESNFNTQATNR). 


\section{Influence of Extraction Mode}

The experiments reported were carried out in acidic solution at $\mathrm{pH}<2$ using trifluoroacetic acid. Under these conditions, application of a negative extraction potential allows detection of deprotonated peptide ions $[7,20]$. To test the effect of esterification on the ion yield of derivatized anionic species, binary mixtures containing unmodified peptides and their hexyl esters were selected for mass spectrometric analysis in both polarity regimes. Figure 3 illustrates few examples corresponding to the MALDI spectra of bradykinin, angiotensin II, and a peptide obtained by proteolytic digestion of chicken lysozyme (FESNFNTQATNR) respectively. A summary of the observed intensity ratios of the unmodified and derivatized peptide ions in their protonated and deprotonated forms is provided in Table 1 for all peptide sequences used in this study. These results reinforce the idea that esterification generally results in an increased detection of the derivatized protonated peptide ion whereas acquisition in negative ion mode generates spectra in which deprotonated ions of the unmodified peptides are the dominant species. Unlike positive extraction mode, the effect of esterification is much more severe on detection of anions suppressing completely the formation of the deprotonated esters. Although almost all the experiments were carried out using 1-hexanol, the deleterious impact of esterification on the formation of negatively charged peptide ester ions and the concomitant augmentation of signal from the protonated ions was observed even when other alcohols were utilized for derivatization. During ion formation, both positive and negative ions are gener-
Table 1. The values in the columns represent the observed intensity ratios of the underivatized and esterified peptide ions acquired in both polarity regimes

\begin{tabular}{|c|c|c|}
\hline Sequence & $\begin{array}{l}{[\text { ester }+\mathrm{H}]^{+} /} \\
{[\text {acid }+\mathrm{H}]^{+}}\end{array}$ & $\begin{array}{c}\text { [ester }-\mathrm{H}]^{-} / \\
{[\text {acid }-\mathrm{H}]^{-}}\end{array}$ \\
\hline DRVYIHPF & 9.2 & 0 \\
\hline KTQHPG & 5 & 0 \\
\hline $\begin{array}{l}\text { Sar-RVYVHPG [Sar }{ }^{1}, \\
\text { Gly }^{8} \text { ]-Angiotensin II }\end{array}$ & 2.8 & 0.1 \\
\hline NRVYVHPF & 1.2 & 0 \\
\hline KRQHPG & 3.2 & 0 \\
\hline RPPGFSPFR & 1.8 & 0 \\
\hline RPPGF & 2.8 & 0 \\
\hline RPPGFSP & 3.1 & 0 \\
\hline GYSLGNWVCAAK* & 2 & 0 \\
\hline CKGTDVQAWIR* & 2.1 & 0 \\
\hline NTDGSTDYGILQINSR* & 1.25 & 0 \\
\hline FESNFNTQATNR & 5 & 0.3 \\
\hline DRVYIHPFMW & 2 & 0 \\
\hline VEADIAGHQEVLIR & 1.5 & 0.1 \\
\hline
\end{tabular}

*The peptides indicated with asterisk* were derivatized with ethanol whereas the others were treated with 1-hexanol.

ated, and only the voltage polarity allows discrimination of the ions extracted from the ion source and detected in the mass spectrum. As a consequence, the initial number of molecules is subjected to competing ionization events for generating positive and negative ions. Analyte is assumed to be ionized mostly via secondary reactions occurring in gas-phase in accordance with the theory proposed by Knochenmuss and Zenobi $[5,21]$. If formation of negative ions is suppressed by esterification, the ionization pathway, which
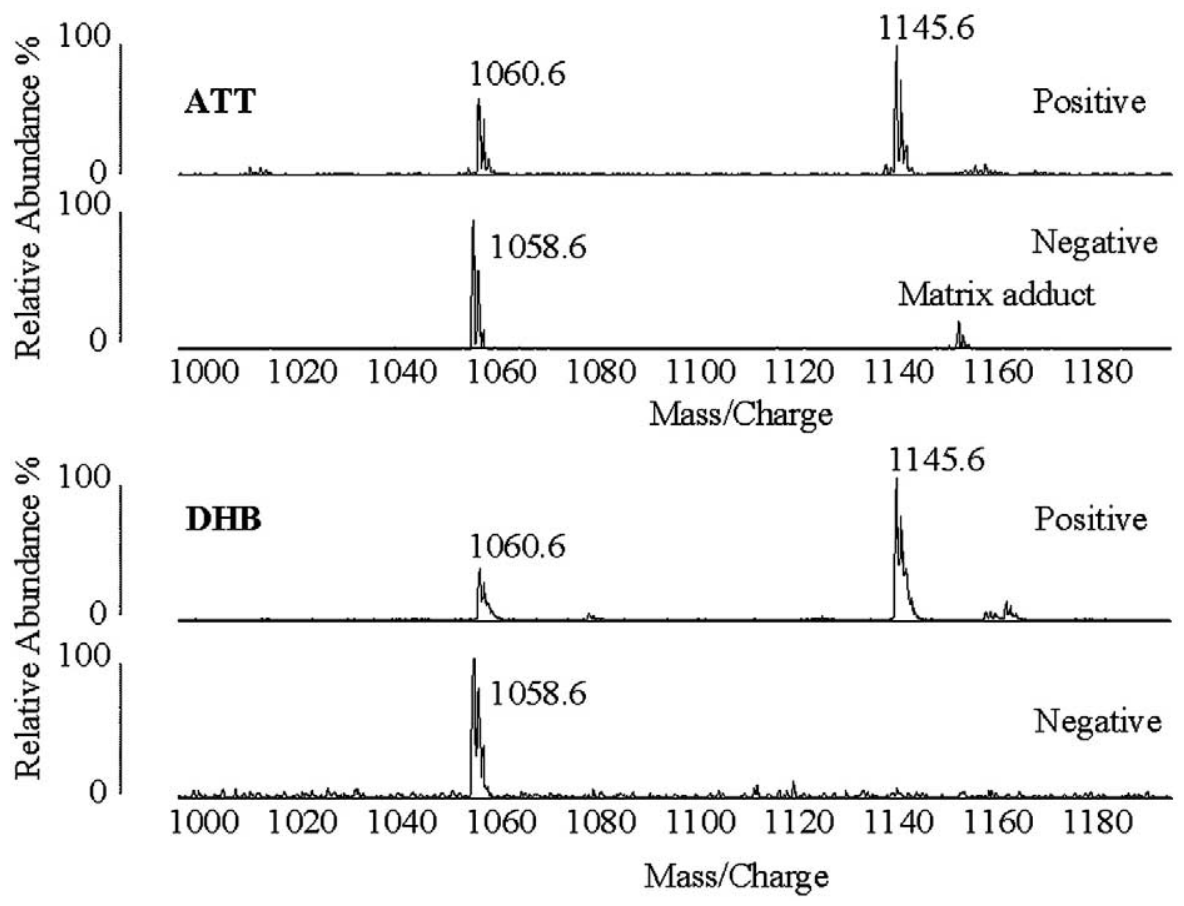

Figure 4. Positive and negative MALDI TOF spectra of a binary mixture of bradykinin fragment RPPGFSPFR with its hexyl ester prepared in ATT and DHB. 


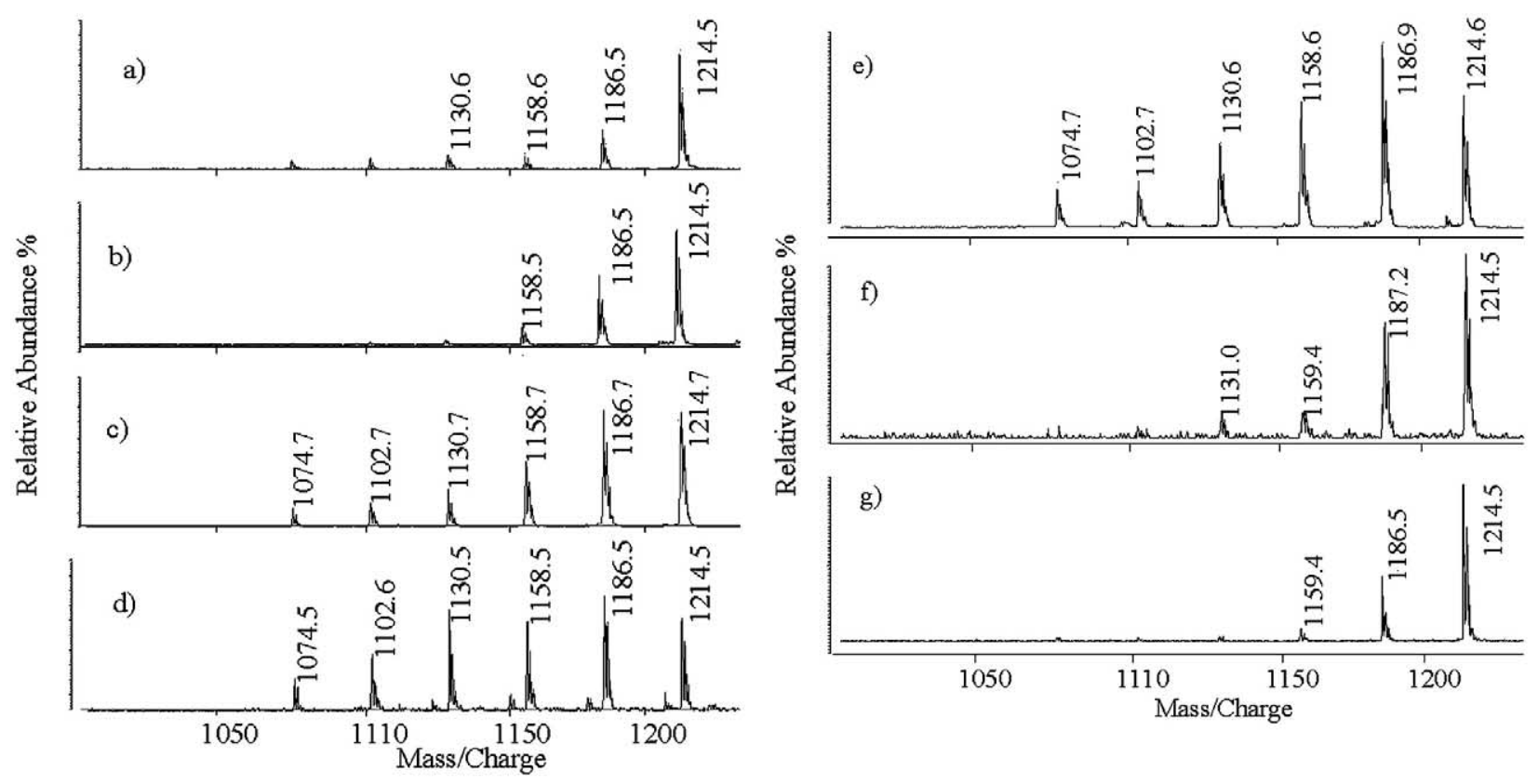

Figure 5. Linear MALDI TOF analysis of an equimolar mixture of angiotensin II esters acquired under the following preparation conditions: (a) ATT $5 \mathrm{mg} / \mathrm{ml}$ in $50 \% \mathrm{CH}_{3} \mathrm{CN}$ (TFA $0.1 \%$ ), (b) DHB 5 $\mathrm{mg} / \mathrm{ml}$ in $50 \% \mathrm{CH}_{3} \mathrm{CN}$ (TFA $0.1 \%$ ), (c) CHCA $5 \mathrm{mg} / \mathrm{ml}$ in $50 \% \mathrm{CH}_{3} \mathrm{CN}$ (TFA $0.1 \%$ ) $+10 \mathrm{mg} / \mathrm{ml}$ fructose, (d) CHCA $5 \mathrm{mg} / \mathrm{ml}$ in $50 \% \mathrm{CH}_{3} \mathrm{CN}+$ ammonium citrate $100 \mathrm{mM}$, (e) CHCA $5 \mathrm{mg} / \mathrm{ml}$ in $50 \%$ $\mathrm{CH}_{3} \mathrm{CN}$ (TFA $0.1 \%$ ) $+5 \mathrm{mg} / \mathrm{ml}$ octyl glucoside, (f) CHCA $2 \mathrm{mg} / \mathrm{ml}$ in $50 \% \mathrm{CH}_{3} \mathrm{CN}$ (TFA $0.1 \%$ ), (e) CHCA $5 \mathrm{mg} / \mathrm{ml}$ in $30 \% \mathrm{CH}_{3} \mathrm{CN}$ (TFA $0.1 \%$ ). The presence of two $-\mathrm{COOH}$ residues in the peptide mixture leads to the formation of esters with the following shifts in MW methanol $(+14 \times 2)$, ethanol $(+28 \times 2)$, 1-propanol $(+42 \times 2)$, 1-butanol $(+56 \times 2)$, 1-pentanol $(+64 \times 2)$ and 1-hexanol $(+84 \times 2)$ respectively. The underlined amino acids indicate the residues containing carboxylic groups.

governs anion formation, is inactivated because of the unavailability of free carboxylic moieties, and a larger fraction of species is shunted to protonation. Under these conditions, esterified protonated peptide ions are detected with higher abundance than their unmodified counterparts. In the absence of esterification, suppression is not prevented, and generation of protonated ions is not favored with respect to anions. Nevertheless, in the analyses of mixtures containing solely esters, in which all the free carboxylic groups were derivatized, ion suppression between ions of different polarities is not observed (data not shown). Therefore, ion yield of deprotonated ions is still governed by the different degree of hydrophobicity, and abundances of derivatized anions are still influenced by the type of alcohol used in the esterification following the trend observed in positive mode.

\section{Influence of Matrix Type and Preparation Conditions}

To verify whether these findings are independent of the matrix used and the type of preparation protocol employed, the peptide mixtures were also prepared in ATT, DHB, and SA before MS analysis. Figure 4 illustrates the MALDI spectra of a binary mixture containing bradykinin and its hexyl ester prepared in DHB and ATT acquired in both polarity regimes. Although ATT is generally utilized for DNA and nucleotide analyses [22], the results are consistent with what is observed in the spectra acquired using CHCA: in the corresponding positive spectra the hexyl ester ion is still the predominant species whereas the deprotonated counterpart is completely absent. A similar trend is also observed when an equimolar mixture containing angiotensin II (DRVYIHPF) and its alkyl ester analogs are analyzed under different preparation conditions. Figure 5 represents a summary of the most significant experiments. Under the concentration used here (picomole level) the change of matrix has shown little effect on the ion abundances of the ester ions (Figure 5a and b). Considering that the spectra were acquired in automatic mode, shot to shot variations in ion signal are observed in spots prepared in DHB and a spectrum with lower signal to noise ratio is generated. Several combinations of CHCA with comatrices were prepared. Fructose, octyl glucoside, and ammonium citrate produce spectra in which the formation of the ion abundance ladder is still observed (Figure 5c, d, e). Using ammonium citrate, no TFA was added in the solution. The peptide mixtures reported here were prepared maintaining constant the concentration of the matrix solution $(5 \mathrm{mg} /$ $\mathrm{ml})$. The impact of the matrix concentration was also studied in a series of experiments in which CHCA concentration was varied from $2 \mathrm{mg} / \mathrm{ml}$ up to12.5 $\mathrm{mg} / \mathrm{ml}$. When a $2 \mathrm{mg} / \mathrm{ml}$ solution of CHCA was used, 
due the smaller number of protonated matrix ions generated in the plume, less intense signals for the ester ions are produced and the sensitivity of the analysis decreased (Figure 5f). However, no significant differences in ion abundance ratios among ester ions were observed. Modification of the solvent composition was employed using a $5 \mathrm{mg} / \mathrm{ml}$ solution of CHCA. Solutions with a lower amount of organic phase (acetone and acetonitrile) generate spectra in which the ester ions containing short alkyl chains (methyl, ethyl, propyl) are nearly absent from the spectrum (Figure $5 \mathrm{~g}$ ). Different preparation protocols were also tested in accordance with the protocols described elsewhere [23]. Under the concentrations used here, (low picomole level), thinlayer and fast evaporation methods produced no substantial differences with respect to the standard dried drop technique in the ion yield ratios of derivatized protonated ions.

\section{Conclusions}

In summary, regardless of the type of matrix and preparation conditions employed, the data suggest that esterification of the $\mathrm{COOH}$ groups influences ion yield at two different stages of ion formation: first, the increase in hydrophobicity facilitates incorporation of the esterified peptide into the matrix crystals. This affects the morphology of the MALDI spot so that the derivatized peptides are preferentially desorbed. From the experiments performed here, the hexyl derivative has the highest propensity in doing so. Second, formation of positive ions in gas-phase also benefits from the suppression effect induced on anions, when free carboxylic groups are derivatized and generation of anion is precluded. The proposed suppression effect appears to be in accordance with in plume reactions described previously $[5,21]$.

\section{References}

1. Tanaka, K.; Waki, H.; Ido, Y.; Akita, S.; Yoshida, Y.; Yoshida, T. Protein and Polymer Analyses up to $m / z$ 100,000 by Laser Ionization Time-of-flight Mass Spectrometry. Rapid Commun. Mass Spectrom. 1988, 2, 151-153.

2. Karas, M.; Hillenkamp, F. Laser Desorption Ionization of Proteins with Molecular Masses exceeding 10,000 Daltons. Anal. Chem. 1988, 60, 2299-2301.

3. Dreisewerd, K. The Desorption Process in MALDI. Chem. Rev. 2003, 103, 395-426.

4. Karas, M.; Kruger, R. Ion Formation in MALDI: The Cluster Ionization Mechanism. Chem. Rev. 2003, 103, 427-440.

5. Knochenmuss, R.; Zenobi, R. MALDI. Ionization: The Role of In-Plume Processes. Chem. Rev. 2003, 103, 441-452.

6. Zenobi, R.; Knochenmuss, R. Ion Formation in MALDI Mass Spectrometry. Mass. Spectrom. Rev. 1998, 17, 337-366.

7. Karas, M.; Gluckmann, M.; Schafer, J. Ionization in MatrixAssisted Laser Desorption/Ionization: Singly Charged Molec- ular Ions are the Lucky Survivors. J. Mass Spectrom. 2000, 35 $1-12$.

8. Olumee, Z.; Sadeghi M.; Tang, X. D.; Vertes, A. Amino Acid Composition and Wavelength Effects in Matrix-Assisted Laser Desorption Ionization. Rapid Commun. Mass Spectrom. 1995, 9, 744-752.

9. Krause, E.; Wenschuh, H.; Jungblut, P. R. The Dominance of Arginine-Containing Peptides in MALDI-Derived Tryptic Mass Fingerprints of Proteins. Anal. Chem. 1999, 71, 41604165.

10. Brancia, F. L.; Oliver, S. G.; Gaskell, S. J. Improved MatrixAssisted Laser Desorption/Ionization Mass Spectrometric Analysis of Tryptic Hydrolysates of Proteins following Guanidination of Lysine-Containing Peptides. Rapid Commun. Mass Spectrom. 2000, 14, 2070-2073.

11. Naven, T. J.; Harvey, D. J. Cationic Derivatization of Oligosaccharides with Girard's T Reagent for Improved Performance in Matrix-Assisted Laser Desorption/Ionization and Electrospray Mass Spectrometry. Rapid Commun. Mass Spectrom. 1996, 10, 829-834.

12. Chou, C. W.; Williams, P.; Limbach, P. A. Matrix Influence on the Formation of Positively charged Oligonucleotides in Matrix-Assisted Laser Desorption Ionization Mass Spectrometry. Int. J. Mass Spectrom. 1999, 193, 15-27.

13. Cohen, S. L.; Chait, B. T. Influence of Matrix Solution Conditions on the MALDI-MS Analysis of Peptides and Proteins. Anal. Chem. 1996, 68, 31-37.

14. Amado, F. M. L.; Domingues, P.; Santana Marques, M. G.; Ferrer Correia, A. J.; Tomer, K. B. Discrimination Effects and Sensitivity Variations in Matrix-Assisted Laser Desorption/ Ionization. Rapid Commun. Mass Spectrom. 1997, 11, 1347-1352.

15. Wang, R.; Chen, L.; Cotter, R. J. Effects of Peptide Hydrophobicity and Charge State on Molecular Ion Yields in Plasma Desorption Mass Spectrometry. Anal. Chem. 1990, 62, $1700-$ 1705.

16. Naylor, S.; Findeis, A. F.; Gibson, B. W.; Williams, D. H. An Approach towards the Complete FAB Analysis of Enzymatic Digests of Peptides and Proteins. J. Am. Chem. Soc. 1986, 108, 6359-6363.

17. Falick, A. M.; Maltby, D. A. Derivatization of Hydrophilic Peptides for Liquid Secondary Ion Mass Spectrometry at the Picomole Level. Anal. Biochem. 1989, 182, 165-169.

18. Valero, M. L.; Giralt, E.; Andreu, D. An Investigation of Residue-Specific Contributions to Peptide Desorption in MALDI-TOF Mass Spectrometry. Lett. Pept. Sci. 1999, 6, 109115.

19. Burkitt, W. I.; Giannakopulos, A. E.; Sideridou, F.; Bashir S.; Derrick, P. J. Discrimination Effect in MALDI-MS of Mixtures of Peptides-Analysis of the Proteome. Aust. J. Chem. 2003, 56, 369-377.

20. Kruger, R.; Karas, M. Formation and Fate of Ion Pairs during MALDI Analysis: Anion Adduct Generation as an Indicative Tool to Determine Ionization Processes. J. Am. Soc. Mass Spectrom. 2002, 13, 1218-1226.

21. Knochenmuss, R. A Quantitative Model of Ultraviolet MatrixAssisted Laser Desorption/Ionization including Analyte Ion Generation. Anal. Chem. 2003, 75, 2199-2207.

22. Lecchi, P.; Le, H. M. T.; Pannell, L. K. 6-Aza-2-Thiothymine: A matrix for MALDI Spectra of Oligonucleotides. Nucl. Acid Res. 1995, 23, 1276-1277.

23. Lecchi, P.; Caprioli, R. M. Matrix Assisted Laser Desorption Mass Spectrometry for Peptide Mapping. In: New Methods in Peptide Mapping for the Characterization of Proteins; Hancock, W. S., Ed.; CRC Press: Boca Raton, FL, 1995. pp. 219-240. 